\title{
Phase Structure and Magnetic Properties of Fe-Nb-B-Pt Type of Bulk Nanocrystalline Alloys
}

\author{
G. ZióŁKowski ${ }^{a, *}$, A. ChrobAK $^{a}$, N. Randrianantoandro ${ }^{b}$, J. KlimontKo ${ }^{a}$ \\ ${ }^{a}$ Institute of Physics, University of Silesia, Uniwersytecka 4, 40-007 Katowice, Poland \\ ${ }^{b}$ LUNAM Université- Université du Maine, Institut des Molécules et des Matériaux du Mans UMR CNRS 6283, \\ Avenue Olivier Messaien, 72085 Le Mans cedex 9, France
}

\begin{abstract}
The paper refers to magnetic and structure properties of the $\left(\mathrm{Fe}_{80} \mathrm{Nb}_{6} \mathrm{~B}_{14}\right)_{1-x} \mathrm{Pt}_{x}(x=0.15,0.3,0.4$ and 0.6$)$ bulk nanocrystalline alloys prepared using the vacuum suction casting technique. The samples were in the form of rods with diameters ranging from $0.5 \mathrm{~mm}$ to $1.5 \mathrm{~mm}$. It was shown that the optimal Pt content is $x=0.4$ with the coercive field equal to $0.2 \mathrm{~T}$ and maximum energy product $|B H|_{\max }=11.2 \mathrm{~kJ} / \mathrm{m}^{3}$. The magnetic properties can be associated with Fe-Pt, Fe and Fe-B phases, depending on the alloy composition.
\end{abstract}

DOI: $10.12693 /$ APhysPolA.126.174

PACS: 81.07.Bc, 75.50.Tt, 75.60.76.80.+y

\section{Introduction}

A progress in modern technologies requires new materials with specific properties for different kind of applications. In the field of magnetism among well known permanent magnets, such as Co-Sm, Fe-Pt or Fe-B-Tb types of compounds $[1,2]$, very promising are Fe-NbB type nanocrystalline alloys. It is well known that such alloys exhibit, in a comparison with their crystalline form, unique and mostly superior magnetic properties [3]. From practical point of view especially interesting are nanocrystalline alloys in the so-called bulk form i.e. rods, ingots etc. with dimensions of the order of several $\mathrm{mm}$ [4]. Recently, we have reported structural and magnetic properties of $\left(\mathrm{Fe}_{80} \mathrm{Nb}_{6} \mathrm{~B}_{14}\right)_{1-x} M_{x}(\mathrm{M}=\mathrm{Au}, \mathrm{Ni}, \mathrm{Gd}, \mathrm{Tb})$ bulk nanocrystalline alloys prepared by vacuum suction casting technique [5]. These preliminary studies reveal that the alloys with $\mathrm{Tb}$ can be considered as high coercive magnetic materials [6], but values of saturation magnetization $\mathrm{M}_{S}$ are relatively low due to antiferromagnetic coupling between $\mathrm{Fe}$ and $\mathrm{Tb}$. Therefore, the aim of this work is to study the phase structure and magnetic properties of the $\left(\mathrm{Fe}_{80} \mathrm{Nb}_{6} \mathrm{~B}_{14}\right)_{1-x} \mathrm{Pt}_{x}(x=0.15,0.3,0.4$, $0.6)$ bulk alloys prepared by vacuum suction casting technique. The study concerns the as cast samples and the influence of cooling rate on magnetic properties was investigated.

\section{Experimental procedure}

The $\left(\mathrm{Fe}_{80} \mathrm{Nb}_{6} \mathrm{~B}_{14}\right)_{1-x} \mathrm{Pt}_{x}(x=0.15,0.3,0.4$ and 0.6$)$ bulk nanocrystalline alloys were prepared using the vacuum suction casting technique (described in [4]). The samples were in the form of rods with diameters $d=$ $1.5 \mathrm{~mm}$ and about $3 \mathrm{~cm}$ in length. Moreover, for the $\left(\mathrm{Fe}_{80} \mathrm{Nb}_{6} \mathrm{~B}_{14}\right)_{0.6} \mathrm{Pt}_{0.4}$ compound the samples with additional diameter $d=1 \mathrm{~mm}$ and $d=0.5 \mathrm{~mm}$ were also

*corresponding author; e-mail: gziolkowski@us.edu.pl prepared. Magnetic properties were tested by means of SQUID magnetometer (XL-7, Quantum Design) in magnetic fields up to $7 \mathrm{~T}$ and temperatures $2 \mathrm{~K}-300 \mathrm{~K}$. Phase identification was performed with the use of X-ray diffraction (PANalytical Empyrean) using $\mathrm{Cu}_{\alpha}$ radiation.

\section{Results and discussion}

Figure 1 presents magnetic hysteresis loops measured at room temperature for the samples of $1.5 \mathrm{~mm}$ in diameter and $x=0.15,0.3,0.4,0.6$. At room tempera-

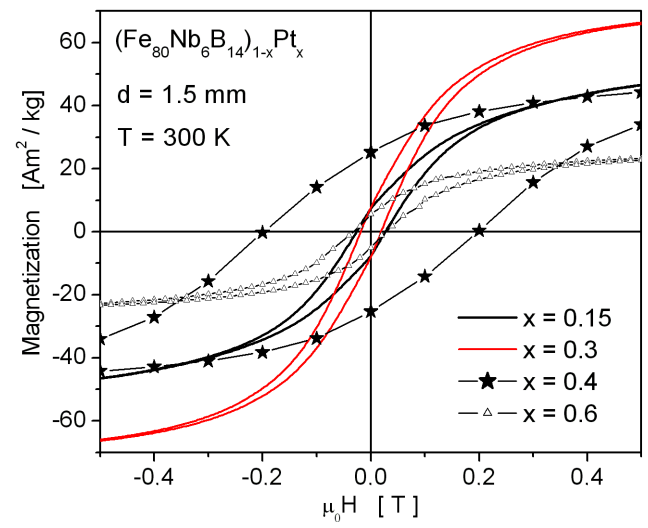

Fig. 1. Hysteresis loops for the $\left(\mathrm{Fe}_{80} \mathrm{Nb}_{6} \mathrm{~B}_{14}\right)_{1-x} \mathrm{Pt}_{x}$ alloys with $d=1.5 \mathrm{~mm}$, measured at $300 \mathrm{~K}$.

ture, the best hard magnetic properties are obtained for the $\left(\mathrm{Fe}_{80} \mathrm{Nb}_{6} \mathrm{~B}_{14}\right)_{0.6} \mathrm{Pt}_{0.4}$ compound with coercive field $\mu_{0} H_{C}$, saturation magnetization $M_{S}$ and maximum energy product $|B H|_{\max }$ equal to $0.2 \mathrm{~T}, 67 \mathrm{~A} \cdot \mathrm{m}^{2} / \mathrm{kg}$ and $11.2 \mathrm{~kJ} / \mathrm{m}^{3}$, respectively. In the case of the alloys with lower $(x=0.15,0.3) \mathrm{Pt}$ content the higher values of $M_{S}$ (up to $75 \mathrm{~A} \cdot \mathrm{m}^{2} / \mathrm{kg}$ for $x=0.3$ ) were observed, however with relatively low coercive field about $0.02 \mathrm{~T}$. The $\left(\mathrm{Fe}_{80} \mathrm{Nb}_{6} \mathrm{~B}_{14}\right)_{0.4} \mathrm{Pt}_{0.6}$ compound can be characterized by the coercive field equal to $0.03 \mathrm{~T}$ and a lower value of 
saturation magnetization $\left(31 \mathrm{~A} \cdot \mathrm{m}^{2} / \mathrm{kg}\right)$ due to the low iron content. Figures 2 and 3 present magnetic hysteresis loops of $\left(\mathrm{Fe}_{80} \mathrm{Nb}_{6} \mathrm{~B}_{14}\right)_{0.6} \mathrm{Pt}_{0.4}$ alloy determined for different $d$ values and at different measurement temperature $T$, respectively. As it is shown, changing of diameter value does not causes remarkable changes of the magnetic properties. As one can expect, the decrease of measurement temperature $T$ leads to higher values of $\mu_{0} H_{C}$ (up to $0.27 \mathrm{~T}$ ) and $M_{S}$ (up to $70 \mathrm{~A} \cdot \mathrm{m}^{2} / \mathrm{kg}$ ), determined at $2 \mathrm{~K}$. The magnetic properties including coercive field $\mu_{0} H_{C}$, saturation magnetization $M_{S}$ (determined at the highest $H$ value) and remanence $M_{r}$ values with the phase structure content (determined based on the X-ray diffraction) for all investigated alloys are listed in Table. For all studied alloys, the main magnetic phase fcc-FePt (A1) has face centered cubic structure which is magnetically relatively soft. Moreover, from broadening of diffraction peaks (not shown here) the mean diameters of the crystallites were estimated to be about $10 \mathrm{~nm}$ for all examined cases.

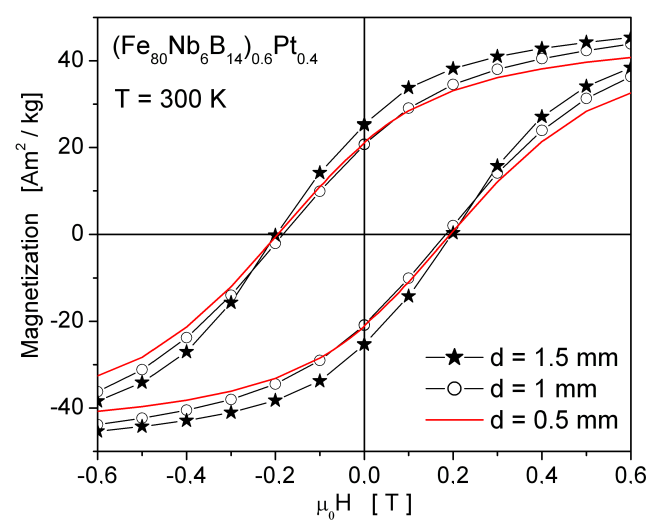

Fig. 2. Hysteresis loops for the $\left(\mathrm{Fe}_{80} \mathrm{Nb}_{6} \mathrm{~B}_{14}\right)_{0.6} \mathrm{Pt}_{0.4}$ alloy samples with different diameters.

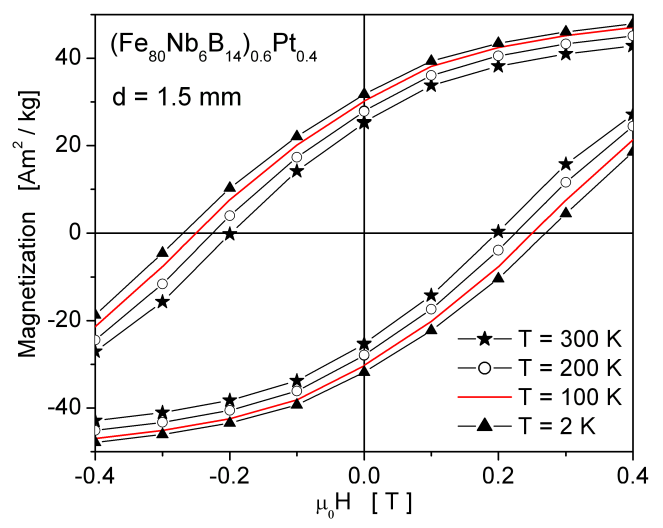

Fig. 3. Hysteresis loops for the $\left(\mathrm{Fe}_{80} \mathrm{Nb}_{6} \mathrm{~B}_{14}\right)_{0.4} \mathrm{Pt}_{0.6}$ alloy sample with $d=1.5 \mathrm{~mm}$, measured at different temperatures.

Let's note that in the case of the alloy with 40 at.\% of Pt the observed magnetic hardening is rather connected with a specific nanostructure than with the formed phases. Moreover, the phase composition does not depend on the sample diameter which is consistent with the magnetic measurements. In contrast to this, for the alloys with $x=0.15,0.3$ and 0.6 one can observe a mixture of soft magnetic phases as fcc-FePt, $\alpha$-Fe, $\mathrm{Fe}_{2} \mathrm{~B}$ and $\mathrm{FePt}_{3}$. It seems that the desired hard magnetic phase, i.e. tetragonal FePt phase (L10) should be formed by an application of heat treatment, that is in our interest and will be studied in the future.

TABLE

Some magnetic parameters determined from the measured hysteresis loops (see the text) and phase structure, detected by XRD.

\begin{tabular}{c|c|c|c|c|c}
\hline \hline $\begin{array}{c}\text { All. } \\
x\end{array}$ & $\begin{array}{c}d \\
(\mathrm{~mm})\end{array}$ & $\begin{array}{c}\mu_{0} H_{C} \\
(\mathrm{~T})\end{array}$ & $\begin{array}{c}M_{s} \\
\left(\frac{\mathrm{Am} \mathrm{m}^{2}}{\mathrm{~kg}}\right)\end{array}$ & Phases \\
\hline 0.15 & 1.5 & 0.026 & 71 & 7.5 & fcc-FePt $2 \%, \mathrm{Fe} 72 \%, \mathrm{Fe}_{2} \mathrm{~B} 26 \%$ \\
\hline 0.3 & 1.5 & 0.019 & 75 & 8 & fcc-FePt $80 \%, \mathrm{Fe} 9 \%, \mathrm{Fe}_{2} \mathrm{~B} 11 \%$ \\
\hline 0.4 & 1.5 & 0.2 & 67 & 25 & fcc-FePt $100 \%$ \\
\hline 0.4 & 1 & 0.182 & 65 & 21 & fcc-FePt $86 \%, \mathrm{Fe} 2 \%, \mathrm{FePt}_{3} 12 \%$ \\
\hline 0.4 & 0.5 & 0.195 & 62 & 21 & not measured \\
\hline 0.6 & 1.5 & 0.032 & 31 & 5.5 & fcc-FePt $72 \%, \mathrm{Fe}_{2} \mathrm{~B} 28 \%$
\end{tabular}

\section{Conclusions}

At this stage of our study, related to the as cast $\left(\mathrm{Fe}_{80} \mathrm{Nb}_{6} \mathrm{~B}_{14}\right)_{1-x} \mathrm{Pt}_{x}$ bulk nanocrystalline alloys prepared by vacuum suction casting technique, the main conclusions can be summarized as follows.

The as cast bulk nanocrystalline rod consists of a mixture of fcc-FePt, binary iron borides $\left(\mathrm{Fe}_{2} \mathrm{~B}\right)$ and $\alpha$-Fe phases with mean crystallites diameters of about $10 \mathrm{~nm}$.

The best hard magnetic properties were observed for $x=0.4$ i.e. $\mu_{0} H_{c}=0.2 \mathrm{~T}$ and $|B H|_{\max }=11.2 \mathrm{~kJ} / \mathrm{m}^{3}$.

The magnetic properties seem to be insensitive to the changes in diameter, which means that the obtained cooling rate for applied moulds is not sufficient to change the microstructure of such compounds.

\section{Acknowledgments}

Grzegorz Ziółkowski acknowledges a scholarship from the TWING project co-financed by the European Social Fund. The grant from French government is also appreciated.

\section{References}

[1] K.H.J. Buschow, F.R. de Boer, Physics of magnetism and magnetic materials, Kluwer Academic Publishers, Amsterdam 2004.

[2] N. Randrianantoandro, A.D. Crisan, O. Crisan, J. Marcin, J. Kovac, J. Hanko, J.M. Grenèche, P. Svec, A. Chrobak, and I. Skorvanek, J. Appl. Phys. 108, 093910 (2010).

[3] A. Chrobak, D. Chrobak, G. Haneczok, P. Kwapuliński, Z. Kwolek and M. Karolus, Mater. Sci. Eng. A 382, 401 (2004).

[4] A. Chrobak, M. Karolus, G. Haneczok, Solid State Phenomena 163, 233 (2010).

[5] G. Ziółkowski, N. Randrianantoandro, A. Chrobak, J. Klimontko, M. Kądziołka-Gaweł , G. Haneczok, Acta Phys. Pol. A 121, 1266 (2012).

[6] A. Chrobak G. Ziółkowski, N. Randrianantoandro, J. Klimontko, G. Haneczok, J. Alloys Compd. 537 , 154 (2012). 